\title{
Assessing multifunctional innovation adoption via an integrative model
}

\author{
Maria Sääksjärvi • Saeed Samiee
}

Received: 4 January 2010 / Accepted: 6 October 2010 / Published online: 3 November 2010

(C) The Author(s) 2010. This article is published with open access at Springerlink.com

\begin{abstract}
This study proposes and tests an integrative model that incorporates the mental resources framework (MOA: motivation, opportunity, and ability) alongside traditional innovation adoption predictors for assessing the adoption of dual-functionality innovations (DFI), a special case of multifunctional innovations (MFI). The multifunctional nature of an increasing number of new products demands the use of mental resources in evaluating new offers, as the comprehension of MFIs is more demanding (i.e., requires more mental resources) than singlefunctionality (SF) products. The proposed model also recognizes the role of MFI categorization as a critical link in the process, because an MFI, and within the context of our study a DFI, helps consumers achieve multiple goals if they realize its dual functionality. Our model demonstrates that mental resources play a significant role in consumers' adoption decisions and should be included in studies of MFI adoption. Further, our integrative model offers a significant improvement over rival alternatives that use only traditional innovation adoption predictors. Thus, the model offers a new approach for estimating MFI adoption with a superior predictive power and facilitates the development of appropriate marketing strategies for such products.
\end{abstract}

Financial support for this project from the Academy of Finland is gratefully acknowledged.

M. Sääksjärvi

Delft University of Technology,

Delft, The Netherlands

S. Samiee $(\bowtie)$

Collins College of Business, The University of Tulsa,

800 South Tucker Drive,

Tulsa, OK 74104-9700, USA

e-mail: ssamiee@utulsa.edu
Keywords Motivational resources - Multifunctional products · Innovation adoption · Integrative model

A frequent practice in high-tech markets is to introduce new products that repackage existing functionalities into a new format. For example, Apple's iPod, which is widely regarded as a highly innovative product, is actually a combination of podcasting (developed by Userland Software), PortalPlayer software, and standard MP3 player hardware. The popular trend toward this technological convergence crosses category boundaries and has increasingly made single-functionality (SF) products, particularly in consumer electronics, more of an exception. Personal computers, for example, can perform numerous audio and video functions in addition to running office and game software. Cellular phones too do much more than remote telephony and have become multimedia centers with camera, TV, video, Internet, and games. ${ }^{1}$ Apple's iPhone, for example, is "so packed with possibilities that the cell phone may actually be the least interesting part" (Pogue 2007).

As high-tech innovations become increasingly multifunctional, consumers face a decision-making process which differs from that of traditional products. Of prime importance in this regard are the consumer categorization of multifunctional (MF) products and the motivational resources consumers invest in the adoption process. Hightech products in general, and multifunctional innovations (MFIs) in particular, increase consumer confusion (Mick and Fournier 1998), frustration (Wood and Moreau 2006),

\footnotetext{
${ }^{1}$ Corporate product strategies increasingly aim to build added functionality in existing products. For example, Intel imbeds previously independent components of the PC in its processors. Its Centrino platform combines processors with chipsets supporting wireless LAN and newer processors incorporate the PC's RAM modules.
} 
and indecision regarding the product's main functionality (Ziamou and Ratneshwar 2003) in the adoption process. The dual-functionality innovation (DFI) examples shown in Table 1 demonstrate the gap between firm-level positioning and market-level interpretation. ${ }^{2}$ Such gaps will likely result in confusion and miscategorization and, hence, inhibit the adoption process, unless substantial mental resources are devoted to categorizing the product. Thus, addressing consumer categorization of MF products in combination with motivational resources is an issue that deserves further attention.

Motivational resources play a key role in the categorization and adoption of a product and can often create pathways for seeing a new product in a different light (Rogers 2003). The literature calls for developing models that incorporate motivational resources to improve estimates of innovation adoption (e.g., Gregan-Paxton et al. 2005; Moreau et al. 2001; Rogers 2003); this has yet to be answered. Consistent with this recommendation, we integrate the mental resources framework with innovation adoption measures to propose and test an integrative model that includes consumers' motivational resources as well as the traditional innovation adoption measures for assessing consumer adoption of MFIs.

\section{Conceptual foundation}

Our conceptual framework acknowledges the role of product functionality and, within the context of MFIs, dual functionality. To understand the concept of dual functionality, we rely on the conceptual combination literature from cognitive psychology that focuses on how consumers combine two or more product categories into one. According to the literature, consumers integrate concepts by using one category to modify the representation of the other category (Wisniewski 1997; Wisniewski and Love 1998). However, combining concepts alters them; that is, when the original (primary) category is crossed with the other (supplemental) category, it creates a new member of the primary category. When combining concepts, consumers [should] realize that the product has several functionalities (Gill and Dubé 2007). Otherwise, the consumer will miss out on the specific goals and benefits

\footnotetext{
${ }^{2}$ For the purposes of this research, dual-functionality innovations are considered a special case of multifunctional innovations (for a similar approach, see Gregan-Paxton et al. 2005). Therefore, the term MFI is generically used throughout the study to include DFIs; however, the focus of the empirical portion of our study is strictly on DFIs as recommended in the literature (Gill 2008). The use of DFIs in the design and testing of our model (instead of MFIs) affords us more accurate estimates of the posited effects and a straightforward interpretation of the results.
}

provided by the product (Gill and Dubé 2007). As such, an "objectively correct" categorization of dual-functionality products exists in which the consumer blends the functionalities of the primary and the supplemental categories to reach a DF categorization of the products (Gill and Dubé 2007).

Functionality refers to the opportunity of action afforded by a product (Ziamou and Ratneshwar 2003). A particular functionality is associated with a particular product category (Markman 2001). When considering a DFI, consumers adjust their concepts of the two functionalities associated with the product categories to fit them to the new product. For example, when hearing the category "cell phone PDA," consumers automatically think of the functionality associated with PDAs, and modify the PDA product category with the functionality of cell phones until they arrive at an understanding of the integrated concept "cell phone PDA" (Wisniewski 1995). We use the term dual functionality to refer to a product consisting of two product categories with two functionalities that consumers are expected to integrate (Gill and Dubé 2007; Wisniewski 1995). In this integration, consumers also note the complementary role played by the product categories that are combined in the DF product name, thereby automatically identifying a thematic relation between the primary and the supplemental category (Gagné and Shoben 1997). This complementary role highlights the use of the dual-functionality product as a specific instance of the primary category (Gagné and Shoben 1997). For example, "camera cell phone" denotes a particular kind of cell phone with a specific use, such as "a cell phone with a camera to be used when on-the-go." Thus, when seeing the category names for dual-functionality products, people automatically think of both the functionalities of the product as well as its use.

Because they require the interpretation of multiple categories, the comprehension of MFIs is more demanding (i.e., requiring more mental resources) than SF products (Gregan-Paxton et al. 2005). The conceptual framework for this study is, therefore, designed to complement the traditional innovation adoption model initially developed by Rogers and subsequently built upon by other researchers to understand consumer adoption of MFIs. Our key objective is attaining a superior predictive power of MFI adoption by integrating two important areas within marketing: the mental resources framework (MacInnis et al. 1991) and the innovation characteristics from the adoption innovations model (Rogers 1962). Mental resources are used to process new information and are comprised of motivation, opportunity, and ability (MOA). The MOA model was originally developed in an advertising context (MacInnis et al. 1991). For the purposes of this investigation, we adapt and extend the original MOA model to fit an MFI context. Previous studies utilizing the MOA framework have also found it 
Table 1 Firm positioning vs. market interpretation

\begin{tabular}{|c|c|c|c|}
\hline Firm & Innovation & Firm-level positioning objective & Market-level interpretation \\
\hline Nokia & N90 & $\begin{array}{l}\text { "pro-photo-taker, personal moviemaker" } \\
\text { (www.nokia.com/nseries) }\end{array}$ & $\begin{array}{l}\text { "cell phone" and a "camera phone... in a class } \\
\text { by itself" (Business Week, January 9, 2006) }\end{array}$ \\
\hline Casio & wrist camera watch & $\begin{array}{l}\text { "A mixture between a digital camera and } \\
\text { a watch" (www.watchzworld.com) }\end{array}$ & A gadget-like watch (bloggers at www.epinions.com) \\
\hline Samsung & media mobile & $\begin{array}{c}\text { "multimedia masterpiece" } \\
\text { (www.samsung.com) }\end{array}$ & simply a "phone" (CNET review and user comments) \\
\hline Sony Ericsson & Walkman phone & $\begin{array}{l}\text { "complete music kit" } \\
\text { (www.sonyericsson.com) }\end{array}$ & $\begin{array}{l}\text { A phone. "Can someone please tell me what makes } \\
\text { this a "Walkman cell phone' besides the fact that it has } \\
\text { the Walkman W on it?" (www.engadget.com) }\end{array}$ \\
\hline
\end{tabular}

necessary to adapt and extend the original MOA framework to make it applicable to such contexts as innovations (Wu et al. 2004), value creation (Gruen et al. 2007), organizational performance (Clark et al. 2005), and social marketing (Binney et al. 2003).

The first component of the MOA framework, motivation, is defined as the desire to process new information and reflects the readiness and intention of consumers to interpret new products (MacInnis et al. 1991). In relation to new products, motivation consists of any factor that makes consumers consider the new product ( $\mathrm{Wu}$ et al. 2004). Following the pertinent literature, in a DFI context, motivation is represented by consumers' feelings toward technology (technological anxiety) and perceived enjoyment from interacting with technological devices (playfulness), which have been shown to play pivotal roles in consumers' reactions toward technology (Meuter et al. 2005). Opportunity, the second component, is defined as conditions that facilitate or inhibit the extent of the processing of new products (Gruen et al. 2007). Within the context of DF products, opportunity is represented by the chance to accurately categorize the DFI as a dual-functionality product. In general, MF products can be defined as low-opportunity products (cf. Batra and Ray 1986) since they are difficult to process. Such a view is consistent with the innovation adoption literature (in which MF products are represented as a specific processing opportunity) and is also in line with other studies on new products and MOA that refer to opportunity as a constraint imposed by a particular product group or market situation (Wu et al. 2004). The third component of the MOA framework, ability, refers to the consumer's skill or proficiency in interpreting new information (MacInnis and Jaworski 1989) and is represented by prior knowledge relevant to given product categories (Batra and Ray 1986). Regarding MFIs, the ability to process new information is represented by knowledge and need for cognition and involvement, which have been found to be instrumental in interpreting new products (Wood and Swait 2002; Zaichkowsky 1985).
Three considerations bolster the use of the MOA framework in conjunction with the traditional innovation adoption model for predicting consumer sentiments toward MFIs. First, MOA encourages more careful consideration of new products (Wu et al. 2004). This process is essential in the case of MF products, which are mentally resourceintensive to comprehend. Second, the MOA factors encourage consumers to more openly interpret novel products and consider multiple interpretations of situations (Batra and Ray 1986), which fits the framework of MF products that can be categorized in multiple ways. Finally, the MOA factors have been shown to encourage matching between messages and product type (Liebermann and Flint-Goor 1996), which fits the context of MF innovations that require integration of product information. The two latter points are of particular importance to MFIs, since they pertain to the MFI categorization as a dual-functionality product within the context of the present investigation.

The innovation adoption framework (Rogers 1962, 2003), in turn, focuses on how consumers evaluate new products based on innovation characteristics, such as a product's relative advantages, risk, compatibility, and complexity. Taken together, the MOA factors should (1) encourage deeper and more thorough evaluation of an MF product, (2) help consumers accurately categorize the MF product as a dual-functionality one, and (3) influence the way consumers view the innovation characteristics proposed by Rogers.

Our proposed integrative model is shown in Fig. 1. The MOA factors will be discussed in the order in which they appear in our model; hence, we start with ability, continue with opportunity, and finally discuss motivation.

Ability

Not all consumers are equally equipped to categorize new products (Petty et al. 1983). Consumers' knowledge, or familiarity and expertise, determines their ability to categorize new products and consequently guides their com- 
Fig. 1 Dual-functionality (DF) innovation adoption process

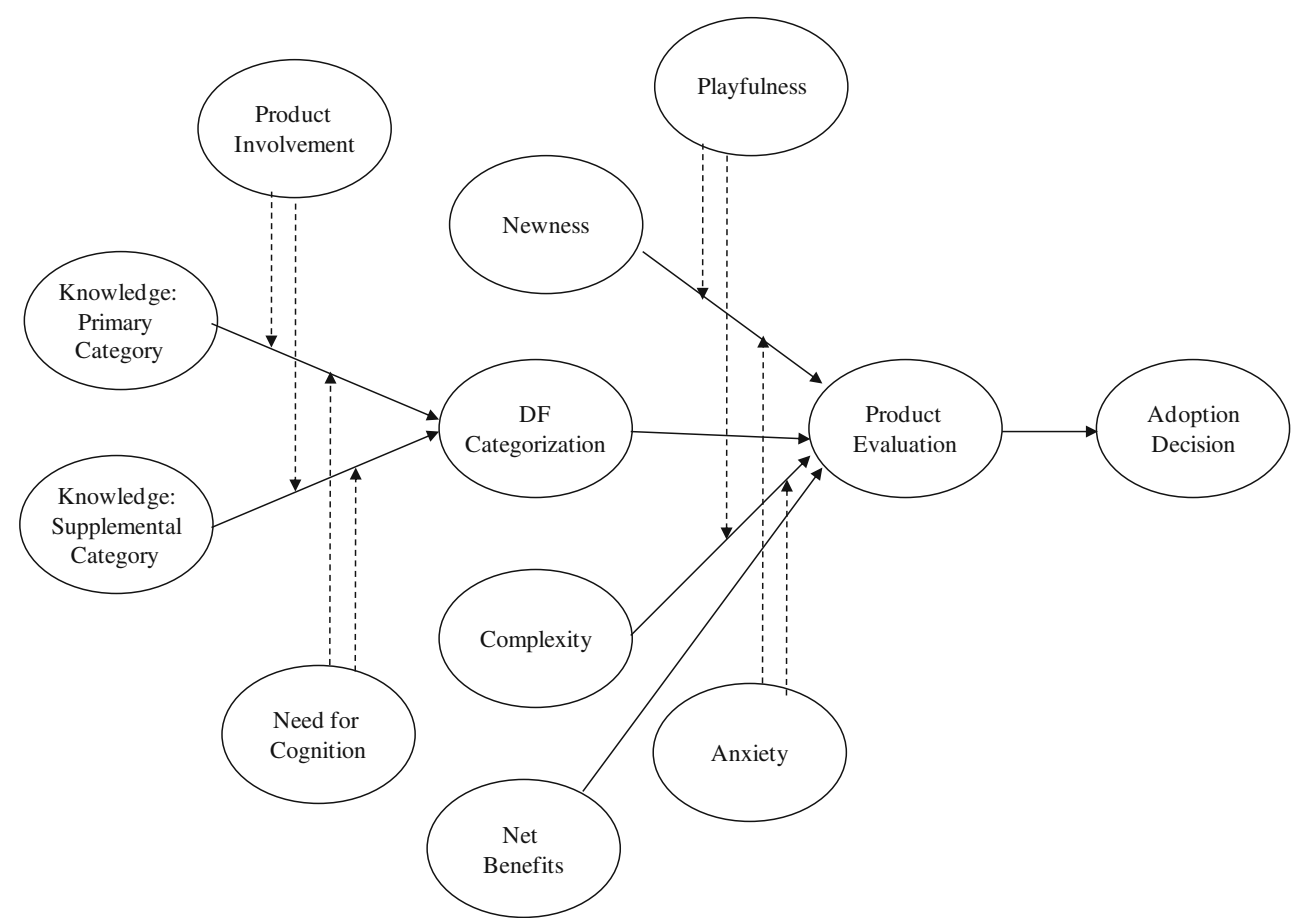

prehension of the MFIs (Alba and Hutchinson 1987). In particular, high-tech products are complex and are often described in technical terms, and therefore knowledge of the relevant product category is imperative for assessing product benefits and functionality.

In learning about DFIs, consumers can possess knowledge about two product categories - the "primary" and "supplemental" categories (Gill and Dubé 2007; Gill 2008; Moreau et al. 2001). Consistent with the literature, we define the primary product category as the one that most resembles the innovation in terms of functionality. In the English language, this product category is listed as the right-most category in a category label (Gagné and Shoben 1997; Wisniewski 1997; Wisniewski and Love 1998). The supplemental category signifies how the DFI differs from other primary category products (Moreau et al. 2001; Wisniewski 1997). This product category is listed as the left-most category in a category label (Gagné and Shoben 1997; Wisniewski 1997; Wisniewski and Love 1998). For example, in the case of a DFI such as a "camera cell phone," "cell phone" is the primary category and "camera" is the supplemental category that signals to consumers this cell phone can also be used as a camera and is, therefore, distinct from ordinary cell phones.

Experts in both primary and supplemental categories possess more knowledge than do novices (Alba and Hutchinson 1987). That is, experts have more elaborate knowledge structures and richer product attribute representations and connections. Thus, they are more likely than novices are to realize the DFI's dual functionality and correctly categorize the product as such. They see the discrepancy between the DFI and other category products and can correctly see what separates the DFI from others. Novices, on the other hand, are likely to have trouble visualizing a DFI's dual functionality since their knowledge structures are impoverished. They likely consider the DFI as another category product with added features. The two different types of knowledge are complementary; consumers integrate their knowledge from primary and supplemental categories to reach a DF categorization (Gill and Dubé 2007). Primary category knowledge helps consumers see the improvement in product functionality in the product class and how the product relates to other products in that category. Supplemental category knowledge helps consumers see how a DF product is different from other primary category products (Wisniewski 1996). Thus, the two types of knowledge help consumers in different ways to reach DF categorization.

H1: Primary category knowledge has a positive effect on DF categorization.

H2: Supplemental category knowledge has a positive effect on DF categorization.

So far, we have assumed that adequate resources are available to categorize a DF product. When substantial resources are not allocated to the categorization process, even experts may have difficulty in seeing the DF product 
as having two functionalities. This assertion follows from the earlier observation that correctly categorizing a DF product can be relatively effortful.

Two types of mental resources, i.e., need for cognition and product involvement, have been shown to enhance correct categorization of a new product. Following Cacioppo and Petty (1982), need for cognition (NFC) is "the difference among individuals in their tendency to engage in and enjoy thinking." The effect of knowledge on MFI categorization is likely to be influenced by NFC. Numerous studies have demonstrated that individuals with a high NFC enjoy elaborating on new product information and consequently engage in detailed processing since it satisfies their goals (e.g., Priluck and Till 2004; Tidwell et al. 2000). Instead of being influenced by peripheral cues such as endorser attractiveness (Haugtvedt et al. 1992), spokesperson credibility (Petty and Cacioppo 1986), or the number of arguments presented (Cacioppo et al. 1983), they tend to be influenced by message-relevant thoughts (Mantel and Kardes 1999). This implies that individuals with a high NFC make careful and well thought-out judgments (Mantel and Kardes 1999).

Within the context of DF products, this would mean that high NFC experts in the primary category pay attention to the product and its functionalities and are thereby more likely to realize its DF purpose. As NFC increases attention to details, high NFC experts in the primary category should be more likely to realize the DF product's dual functionality. Experts in the supplemental category are also aided by NFC. As the supplemental category helps consumers see how the DF product is different from other primary category products (Moreau et al. 2001; Wisniewski 1996), they will elaborate on these differences to a greater extent. In contrast, consumers low in NFC tend to focus on readily available details of the DF product and are thereby unlikely to grasp its dual functionality. Consumers low in NFC tend to categorize products holistically rather than analytically, and they thereby focus on the product's appearance (rather than functionality) in categorization (Creusen and Schoormans 2005). MF products resemble products from the primary category in their appearance, and they encourage consumers low in NFC to consider the MF product to be an SF product (Gregan-Paxton et al. 2005). Since low NFC consumers process neither the primary nor supplemental category in depth, this effect is likely to hold across both categories. Thus, we posit:

H3: For high NFC individuals, expertise in (a) the primary category and (b) the supplemental category is positively related to DF categorization.
H4: For low NFC individuals, expertise in (a) the primary category and (b) the supplemental category is positively related to SF categorization.

Product involvement is the degree to which consumers perceive the personal relevance (Zaichkowsky 1985) or importance of a product category (Mantel and Kardes 1999). Higher levels of involvement have been shown to lead to greater processing of information (e.g., Celsi and Olson 1988; Petty et al. 1983; Richins and Bloch 1986). Highly involved individuals spend more time considering and evaluating accessible attributes during product evaluation (Celsi and Olson 1988).

For high-involvement consumers, knowledge is likely to be positively related to MF categorization. In contrast, if knowledge of the product categories is lacking, the correct categorization of MF products is less likely. High involvement only increases consideration and deliberation of a product if product-related attributes are already accessible from memory (Mantel and Kardes 1999). If high-involvement consumers do not have sufficient knowledge to categorize the new product, the advantages gained from involvement are likely to be lost (Mantel and Kardes 1999). As there are important product-related attributes in the primary and supplemental categories (Wisniewski 1997), we expect this effect to hold for both categories.

Consumers who are involved with a product category have been found to elaborate on products to a broader extent and to a greater degree and to reach more accurate conclusions regarding products than low-involvement consumers (Zaichkowsky 1985). Thus, they should be more likely to be able to correctly categorize a DFI as a dual-functionality product than their low-involvement counterparts. In contrast, for low-involvement consumers, processing a DF product is a taxing process in which they have no incentive to engage. Instead, they tend to rely on categorization cues that are easily visible, such as the product's appearance (Creusen and Schoormans 2005). As DF products tend to look like primary category products, such a categorization strategy is likely to lead consumers to categorize the product as an SF product (Gregan-Paxton et al. 2005). Equal levels of effort are required to process both the primary and supplemental category (Gagné and Shoben 1997); thus, these effects should be visible in both categories.

H5: For high-involvement consumers, (a) primary category knowledge and (b) supplemental category knowledge have a positive effect on DF categorization.

H6: For low-involvement consumers, (a) primary category knowledge and (b) supplemental category knowledge have a positive effect on SF categorization. 


\section{Opportunity}

When faced with an MF product, consumers have the opportunity to categorize it as either an SF or MF product. As compared to SF products, MFIs can contribute to the attainment of multiple goals and are thus likely to be preferred to those that only contribute to a single goal if consumers realize the product's dual functionality (Gill 2008). Multiple goals are preferred to a single goal if consumers view a DF product as having a dual functionality since it evokes goal complementarity (Fishbach and Ferguson 2007; Fishbach and Dhar 2007; Fishbach and Zhang 2008). Complementary goals contribute to a positive product evaluation by suggesting synergistic effects across the goals and highlighting the new (emergent) features of the DF product (Fishbach and Zhang 2008; Kruglanski et al. 2002). ${ }^{3}$ DF products have new features that emerge from the combination of the products (Estes and Ward 2002; Wilkenfeld and Ward 2001), such as multimedia messaging in camera cell phones (which emerges from having a camera and a cell phone in the same package), and highlighting these features increases positive evaluations of the DF product. If consumers see the DF product as having only a single functionality, they are likely to form a more negative view of the product. Missing out on the product's dual functionality is likely to lead to its evaluation as an SF product. As an SF product, MF features are not likely to be that appealing, since the SF counterparts of MFIs are often more powerful and perform better (Han et al. 2009). In this case, consumers are likely to be confused and frustrated about the poor performance of the MF product and find it less attractive. However, recognition of a DFI's dual functionality is likely to lead consumers to accept the lower functionality for the sake of a specific benefit, such as added convenience (Han et al. 2009). For the specific benefit denoted for the DFI, the new attributes that emerge from the combination can come in handy, such as using multimedia messaging with a camera cell phone on-the-go. However, these advantages of a DFI are apparent only if consumers categorize it as such. Given that an SF categorization of a DFI tends to receive lower evaluations (as consumers compare the DFI to SF products) whereas a DFI product categorized as a dual-functionality product tends to receive higher evaluations (as it supports the

\footnotetext{
${ }^{3}$ Dual-functionality products evoke complementary goals by virtue of being integrated in the same package. SF versions of DF products, presented in separate packages, would evoke competing goals (Fishbach and Zhang 2008). This scenario is beyond the scope of this investigation; however, in such cases, the positive effect between DF categorization and product evaluation could become reversed (i.e., negative).
}

attainment of multiple goals and has unique advantages as compared to other products), a positive relationship between DFI categorization (as compared to an SF categorization of the same product) and product evaluation is expected.

H7: Dual-functionality categorization has a positive effect on product evaluation.

\section{Adoption of innovations}

Consumer evaluations of MFIs are influenced by the three attributes of relative advantage, complexity, and compatibility (e.g., Bauer 1960; Rogers 1962, 2003; Tornatzky and Klein 1982). Innovation characteristics initially included two other characteristics: observability and trialability. However, a meta-analysis by Tornatzky and Klein (1982) demonstrated that the effects of these characteristics on adoption were weak. Thus, observability and trialability have not been used in subsequent studies (e.g., Moreau et al. 2001). Two other factors have also emerged as impacting innovation adoption propensity and are often used in conjunction with innovation characteristics: perceived risk (Bauer 1960) and product newness (Robertson 1971). Numerous studies demonstrate the importance of these factors in predicting innovation adoption (Hoeffler 2003; Moreau et al. 2001). The literature has also established that the compatibility and relative advantage dimensions overlap; that is, the more compatible a product, the greater its advantages that are linked to the compatibility of the product (Meuter et al. 2005; Taylor and Todd 1995), as "there can be no advantage to an innovation that does not reflect an adopter's needs" (Moore and Benbasat 1991). Compatibility and complexity have also been suggested to overlap as they both measure learning requirements (Gatignon and Robertson 1985; Moreau et al. 2001). Given this overlap, we capture MFI compatibility through its relative advantage and complexity (cf. Moreau et al. 2001).

The literature on innovation adoption concludes that greater likelihood of product acceptance is positively associated with higher perceived advantage and product newness, ${ }^{4}$ and inversely associated with perceived risk and product complexity (Dickerson and Gentry 1983; Gatignon and Robertson 1985; Holak 1988; Moreau et al. 2001; Rogers 2003; Taylor and Todd 1995). We incorporate advantages of a DFI and its associated risks in our model

\footnotetext{
$\overline{{ }^{4} \text { A positive outcome is expected, as the literature shows that a product }}$ that is new stimulates mental activity to the degree that it is not completely discontinuous with existing knowledge (Campbell and Goodstein 2001; Meyers-Levy and Tybout 1989; Robertson 1971; Szymanski et al. 2007).
} 
via net benefits (advantages-risks). The marketing literature is relatively consistent with respect to the effectiveness of net benefits in predicting adoption of innovations (e.g., Moreau et al. 2001; Wood and Moreau 2006). Taken together, we anticipate that net benefits and newness will have a positive effect and complexity will have a negative effect on product evaluation. In addition to these measures, Rogers $(1962,2003)$ points out that the decision to adopt or reject an innovation is influenced by the consumer's evaluation of the product. Thus, we propose the following hypotheses:

H8: Net benefits have a positive effect on product evaluation. H9: Complexity has a negative effect on product evaluation. H10: Newness has a positive effect on product evaluation. H11: Product evaluation has a positive effect on the adoption decision.

\section{Motivation}

Motivation pertains to the readiness and intention of consumers to interpret new products (MacInnis et al. 1991). The interpretation of technological products is dependent on two important factors: the degree of technological anxiety consumers experience when faced with such products and how playful they feel when interacting with them.

Technological anxiety is the tendency of individuals to be uneasy, apprehensive, or fearful about using technological products (Igbaria and Parasuraman 1989). Technologically anxious consumers demonstrate a lower propensity to interact with complex products, and therefore complexity is likely to be negatively related to the evaluation of DFIs (see Meuter et al. 2003). Technologically sophisticated consumers, on the other hand, are more willing to embrace the more complex DF products. These products tend to be more advanced and perform a wider variety of functions than basic models, may offer customization possibilities and, since not all consumers know how to effectively use technologically sophisticated devices, they can even boost a consumer's ego (Holak 1988; Holak and Lehmann 1990). As such, we expect:

H12a: For more anxious consumers, complexity is negatively related to DFI evaluation.

H12b: For less anxious consumers, complexity is positively related to DFI evaluation.

Consumer reaction to the newness of products is also influenced by technological anxiety (Meuter et al. 2005). MFIs constitute new products, which have been found to heighten uncertainty (Hoeffler 2003). Technologically anxious consumers experience difficulty managing such uncertainties. Anxious consumers experience a negative emotional reaction toward new products that evokes fear and confusion (Venkatesh 2000). The situation escalates given the ambiguous nature of MFIs. In contrast, new products represent a learning opportunity for technologically sophisticated consumers. Technologically confident consumers are likely to enjoy interacting with new products and learning about the benefits they provide. As such, we expect:

H13a: For more anxious consumers, newness is negatively related to DFI evaluation.

$\mathrm{H} 13 \mathrm{~b}$ : For less anxious consumers, newness is positively related to DFI evaluation.

Playfulness is an individual's tendency to interact spontaneously, inventively, and imaginatively with technological products (Webster and Martocchio 1992). It involves a desire for fun, exploration, discovery, challenge, and curiosity (Venkatesh 2000). Playful consumers interact with products for the fun of it and without concern for the utilitarian benefit derived from such interaction (Holbrook et al. 1984). These consumers can imagine using and interacting with MFIs and enjoy products that provide opportunities to use the product in varied ways.

Playfulness is likely to alter consumer perceptions toward product complexity. Although product complexity is traditionally perceived as harmful (Rogers 1962), we propose that playful consumers are likely to enjoy it. Complex products have many features, and playful consumers like to explore new products and discover new ways of using the products. In interacting with products, playful consumers perceive that they exert little effort (Moon and Kim 2001; Venkatesh 2000) and find increased enjoyment in such interactions, even in the case of complex devices (Webster and Martocchio 1993). As such, playful consumers are likely to find product complexity alluring, which enhances their product evaluations. However, for consumers scoring low in playfulness, the evaluation of a product is likely to be weakened by product complexity. These consumers do not enjoy interacting with products and, in particular, complex devices demand heightened effort to do so (Fang et al. 20052006). In this case, product complexity is likely to have a negative effect on product evaluation, because less playful consumers do not enjoy discovering new ways of learning about a new product and, as such, product complexity poses a hurdle for adoption. Thus, we posit:

H14a: For less playful consumers, complexity is negatively related to product evaluation.

H14b: For more playful consumers, complexity is positively related to product evaluation. 
Newness is arousing and prompts product elaboration (Mandler 1982). Furthermore, MFIs are more stimulating when they are moderately new rather than slightly new (Meyers-Levy and Tybout 1989). Playful consumers enjoy elaborating about new products and find the arousal resulting from newness to be stimulating and fun. MFIs are new and require effort to be successfully assessed. Accordingly, in our conceptual framing playfulness interacts with product newness. For playful consumers, resolving the product is likely to be perceived as a fun challenge that they happily engage in as it satisfies their curiosity and provides them with mental stimulation. In contrast, for less playful consumers, newness is likely to be negatively perceived. Assessing a product's newness demands effort and less playful consumers who do not enjoy interacting with new products are likely to feel overwhelmed by them.

H15a: For less playful consumers, newness is negatively related to product evaluation.

H15b: For more playful consumers, newness is positively related to product evaluation.

\section{Methodology}

\section{Study design}

The participants for this investigation were members of a consumer panel consisting of 1,600 business professionals. A random sample of 400 panel members who owned a cell phone was selected, and 250 participated in the study (a response rate of $62.5 \%$ ). A total of 330 product impressions were obtained from respondents, each of whom evaluated one to three multifunctional products and completed a questionnaire. The participants were told that the researcher was interested in their impressions of new products. The questionnaire was sent to the respondents by postal mail. We found no evidence for non-response bias based on age, gender, education, or income $(p<.01)$. Characteristics of the sample are shown in Table 2.

\section{Stimuli}

We use a high-technology product context in our study as recommended in the literature (Gill 2008; Gregan-Paxton et al. 2005). The following DF products were selected as stimuli for this study: camera cell phone, cell phone PDA, PDA watch, and cell phone Internet (a service). We initially conceived ten product announcement formats using publicly available information from business and trade publications and the Internet, coupled with a series of personal interviews with experts familiar with product development. Following
Hirschman and Holbrook (1982), a combination of pictorial and verbal stimuli was used to accurately capture both cognitive and affective consumer responses to new products. To refine and select the stimuli for the main study, we extensively pre-tested our stimuli in two stages.

First, following recommendations from Roberts (2000) and von Hippel (1986), experts from each of the product categories were contacted and asked to help in refining and choosing the most appropriate product announcements (out of the ten initially developed). Next, our experts assisted with the development of the announcements. Our guidelines for the experts specified that the announcements were meant to be realistic and believable in every respect, including being up-to-date with market developments. Five experts in total (one from each product category) assisted in the development and selection of the product announcements that were used in the study. Product category experts also lent assistance in choosing appropriate attributes for presenting each product. Second, product announcements were further pre-tested with 20 consumers for novelty, product benefits, relevancy, and compatibility for the relevant target groups. All of the products were considered novel $(M=4.9)$, relevant $(M=$ 6.2) and compatible $(M=5.5)$ and provided multiple benefits for the relevant target group ( $M=3$ benefits). The categorizations of the products were in line with those of other studies, with most of the pre-test sample considering our DF products to possess a single functionality $(60 \%)$ but with a significant minority $(40 \%)$ considering the DF products to have dual functionality. Based on these pre-tests, we considered the product announcements to be suitable for our study. All pre-test subjects were eventually asked about the dual nature of their respective stimuli. Based on their responses, it is

Table 2 Characteristics of the sample (in \%)

\begin{tabular}{lll}
\hline Gender & Male & 48.1 \\
Age & Female & 51.9 \\
& $18-24$ & 5.7 \\
& $25-34$ & 33.2 \\
& $35-44$ & 31.3 \\
Income & $45-54$ & 35.1 \\
& 55 or older & Nil \\
& Under $\$ 25,000$ & 12.5 \\
Education & \$25,000-\$49,999 & 39.9 \\
& $\$ 50,000-\$ 74,999$ & 24.5 \\
& \$75,000 or more & 14.4 \\
& High school diploma & 20.2 \\
& Some college & 21.6 \\
& College degree & 30.8 \\
& Graduate or professional degree & 24.0 \\
\hline
\end{tabular}


evident that once the nature of the stimuli were disclosed, subjects fully comprehended the dual-functionality of the products, further affirming the appropriateness and complementary nature of the product concepts used to develop each stimulus.

Print announcements for all four products were professionally prepared and shown to the participants in a random fashion to avoid order effects. Each announcement featured the name of the product (in bold print) and a color picture. Below this, nine product properties described the product, three of which were in the primary category, three of which were in the supplemental category, and three of which were shared product properties. Moreover, the body of the copy briefly described the product (see Appendix 1).

\section{Measures}

The majority of measures in our study were adopted from the literature. However, given the paucity of research on MFIs, some measures were developed for the purposes of this study. In line with Anderson and Gerbing (1988), all measures were examined and purified in a measurement model before estimating the structural model. This resulted in measures that were reliable, with items that loaded highly on their intended factor and did not cross-load with other factors.

\section{Ability}

Ability is represented by expertise, familiarity, need for cognition, and product involvement. Expertise was assessed on a ten-item scale measuring factual knowledge about all five product groups involved in the study (cameras, cell phones, PDAs, the Internet, and watches) using a multiple choice/fill in the blanks test (Moreau et al. 2001, Study 2). ${ }^{5}$ Objective measures of familiarity better correspond to the content of consumer knowledge structures (Moreau et al. 2001) and were thus adopted for this research. Need for cognition was measured using Cacioppo et al. (1984) revised 18-item scale. In line with other studies (Cotte and Wood 2004; Kopalle and Lindsey-Mullikin 2003; Shrum et al. 2005), we used a shorter version of the scale,

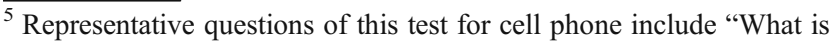
GPS?, (1) global positioning system, (2) general positioning system, (3) global positioning structure, (4) don't know"; for PDAs include "What does USB stand for?, (1) universal smartphone board, (2) universal serial bus, (3) universal standard Bluetooth, (4) don't know"; for watches include "What is the part of the movement that releases the motive power? (1) the fuse, (2) the escapement, (3) the regulator (4) don't know"; and for cameras include "The camera parts which control exposure are the (1) aperture and shutter (2) light meter and f-stop, (3) lens and shutter release, (4) don't know."
}

comprised of six items. These items loaded on a single factor $(\alpha=.81)$. Product category involvement was measured along the ten-item revised personal inventory scale developed by Zaichkowsky (1994) using the five items denoted to measure cognitive involvement. These items also loaded on a single factor $(\alpha=.85)$.

\section{Opportunity}

Consistent with our conceptual framework, opportunity is assessed via categorization. Categorization for each DF product was assessed by asking consumers to state whether the product has a single or dual functionality, followed by a question on the product's categorization. A consumer was given the value 1 if $\mathrm{s} /$ he considered the product to have a single functionality, and 2 if the person considered the product to have a dual functionality. In the categorization question, we gained insight into what product category the respondent thought the product would belong. For example, consumers categorizing a DF product as an SF product consider the camera cell phone as "a cell phone" or "a camera," whereas consumers categorizing a DF product as possessing dual functionality consider it "a camera cell phone" or "a combination of a cell phone and a camera." In the categorization, the complementary roles of the product categories were also often noted, such as a camera cell phone for taking pictures on-the-go, and a PDA watch for keeping up with one's calendar when in between meetings. A member of the research team and a naïve judge (uninformed about our hypotheses) coded the responses based on single vs. dual functionality. The inter-rater reliability (calculated via Cohen's kappa) was 0.96 . Disagreements were resolved by discussion and subsequent consensus.

\section{Innovation measures}

Innovation evaluation measures consist of net benefits, complexity, and newness, and the adoption decision. Following Moreau et al. (2001) and Wood and Moreau (2006), net benefits were measured by asking the participants to list each product's benefits and weaknesses. The difference between the two constitutes net benefits. ${ }^{6}$ Complexity was represented by two items: "complex/not complex" and "difficult/ easy to use" $(\alpha=.76)$, and product newness was assessed in terms of "new/not at all new" and "advanced/not advanced" $(\alpha=.86)$. Product evaluation was measured via an eight-item,

\footnotetext{
${ }^{6}$ We also examined net benefits as a formative construct to determine the differential weights of the benefits and the risks. The weights for benefits and risks were not significantly different: .606 and .621, respectively, thus providing support for our computation of net benefits as the difference between these items.
} 
seven-point scale adapted from Roehm and Sternthal (2001). Of these, five items loaded on a single scale and were included in subsequent analysis $(\alpha=.92)$.

Consumer adoption decisions were measured by an open-ended question that offered respondents an opportunity to accept or reject the DFI, by asking them whether they would buy the product. The open-ended question was subsequently converted into a three-point scale by assessing consumer willingness to buy the DFI (where 1 = would not buy, 2 = purchase would be contingent upon certain conditions, e.g., if s/he could afford it, and $3=$ would buy). ${ }^{7}$

\section{Motivation}

Technological anxiety was measured along a ten-item construct, using seven-point scales adapted from Parasuraman (2000) and Meuter et al. (2003). Five of these items loaded on a single scale and were used for subsequent analysis $(\alpha=.87)$. We combined two existing playfulness scales by Venkatesh (2000) and Moon and Kim (2001) for the technology playfulness scale, which consists of a ten-item, seven-point scale. Of these, nine items loaded on a single factor and were included in subsequent analysis $(\alpha=.92)$.

\section{Data analysis}

We used AMOS 18.0 to test the proposed hypotheses. To avoid dependency in the data structure, the order in which the products were shown to subjects was randomized and included in our model as dummy variables. The order effects were non-significant $(p>.10)$. We also autocorrelated the errors across the four product evaluations to determine whether there is dependency in the data. The correlation coefficients were non-significant $(p>.10)$. Therefore, dependency across product evaluations is not influenced by stimuli order effect, and hence the data for all four DF products were pooled. DF categorization (i.e., single vs. dual functionality) was coded as a dummy variable (0 or 1). AMOS handles dummy variables using Bayesian estimation, in which the means and the intercepts of each variable are calculated using Bayes' theorem and used as analogs to parameter estimates and standard errors (Byrne 2010).

\footnotetext{
${ }^{7}$ The measure was open-ended to allow consumers to reject the innovation, thereby avoiding the pro-innovation bias that is prevalent in innovation studies (Rogers 2003). The pro-innovation bias is particularly prevalent in high-tech products that are often launched because the technology is available, not because it would be beneficial to consumers to upgrade to a new product (Mick and Fournier 1998).
}

\section{Results}

We first examined the fit indices for the estimated model. Since we have a categorical variable in our model, we examined the appropriateness of using the chi-square statistic by estimating the multivariate normality of our variables. The results showed that all of our variables (including the categorical variable) had skewness (.12$1.15)$ and kurtosis (.06-.58) levels well below the accepted threshold (<.2; Schumacker and Lomax 2004), making chisquare testing suitable for our model (Jöreskog and Sörbom 1982). The fit measures show that our model has an acceptable fit: $\chi_{190}{ }^{2}=2.66$, RMSEA $=.071, \mathrm{GFI}=.890$, $\mathrm{AGFI}=.826, \mathrm{NFI}=.921$, and $\mathrm{CFI}=.948$.

Indicator loadings, average variance extracted (AVE), and composite reliability for model constructs are shown in Table 3. As shown in Table 3, the scale purification process resulted in dropping of some items for some scales due to low item-to-total correlation coefficients or low factor loadings. For the resultant scales, each item has a loading that exceeds.60 on its own construct, providing support for their reliability (see Table 3; Fornell and Bookstein 1982). Each item also has a greater loading with its own construct than with other constructs, demonstrating item-level convergent and discriminant validity (Chin 1998). Based on the composite reliability and Cronbach's alpha measures, all scales demonstrated adequate internal consistency (Fornell and Larcker 1981). Convergent validity was assessed by examining the average variance extracted (AVE) for each construct (Chin 1998; Fornell and Larcker 1981). All AVE figures were at least.50, showing support for substantial explained variance in each variable. Discriminant validity was tested by examining whether the AVE of each construct (the average variance shared between a construct and its measures) was greater than the shared variance between the construct and other constructs in the model (square of correlation between the two constructs) (Fornell and Larcker 1981). At the construct level, AVE measures for all variables are greater than their squared correlation coefficients and demonstrate satisfactory discriminant validity (Chin 1998; Fornell and Larcker 1981). Table 4 reports the descriptive statistics and correlation coefficients between the constructs. The path loadings, $t$-values, and significance levels are shown in Table 5.

Primary category knowledge was expected to have a positive effect on DF categorization in our first hypothesis. Our findings support H1 $(\beta=.449, t=1.81, p<.05)$; that is, primary category knowledge demonstrates a positive effect on DF categorization. Our second hypothesis suggests that supplemental category knowledge has a positive effect on DF categorization. Our results show that supplemental category knowledge had no effect $(\beta=.102, t=.42, p>.10)$, and therefore $\mathrm{H} 2$ is not supported. 
Table 3 Loadings, AVE, and composite reliability

\begin{tabular}{|c|c|c|c|c|c|c|c|}
\hline & $\begin{array}{l}\mathrm{NFC} \\
\rho \mathrm{c}=.86 \\
\mathrm{AVE}=.51\end{array}$ & $\begin{array}{l}\mathrm{PI} \\
\rho \mathrm{c}=.89 \\
\mathrm{AVE}=.63\end{array}$ & $\begin{array}{l}\text { PLAY } \\
\rho c=.92 \\
\mathrm{AVE}=.56\end{array}$ & $\begin{array}{l}\text { ANX } \\
\rho c=.91 \\
\mathrm{AVE}=.66\end{array}$ & $\begin{array}{l}\mathrm{COM} \\
\rho c=.89 \\
\mathrm{AVE}=.80\end{array}$ & $\begin{array}{l}\mathrm{NEW} \\
\mathrm{j} \rho \mathrm{c}=.79 \\
\mathrm{AVE}=.66\end{array}$ & $\begin{array}{l}\mathrm{PE} \\
\rho c=.94 \\
\mathrm{AVE}=.76\end{array}$ \\
\hline \multicolumn{8}{|l|}{ Need for Cognition (NFC) } \\
\hline Prefer complex problems & .717 & -.095 & .063 & .202 & -.170 & .184 & -.185 \\
\hline Responsibility for situations & .745 & -.009 & .026 & .135 & -.022 & .083 & -.110 \\
\hline New solutions & .687 & -.054 & .109 & 210 & -.046 & .027 & -.151 \\
\hline Puzzle solving & .767 & -.091 & .155 & .352 & -.110 & .192 & -.209 \\
\hline Abstract thinking & .670 & -.053 & -.073 & .009 & -.048 & -.044 & -.088 \\
\hline Intellectual tasks & .712 & -.028 & .077 & .188 & .017 & .061 & -.060 \\
\hline \multicolumn{8}{|l|}{ Product Involvement (PI) } \\
\hline Important & .013 & .837 & .136 & .076 & .132 & .143 & .306 \\
\hline Relevant & -.033 & .818 & .081 & -.022 & .162 & .041 & .342 \\
\hline Meaningful & -.031 & .793 & .250 & .092 & .130 & .237 & .348 \\
\hline Worthless & -.157 & .717 & .184 & -.019 & .190 & .209 & .431 \\
\hline Needed & -.142 & .812 & .038 & -.190 & .271 & .021 & .562 \\
\hline \multicolumn{8}{|l|}{ Playfulness (PLAY) } \\
\hline Spontaneous & .116 & .107 & .744 & .161 & -.040 & .120 & -.098 \\
\hline Imaginative & .051 & .168 & .805 & .238 & -.100 & .213 & -.077 \\
\hline Flexible & .098 & .129 & .722 & .214 & .006 & .149 & -.014 \\
\hline Creative & .092 & .134 & .809 & .164 & .046 & .147 & .024 \\
\hline Playful & -.011 & .125 & .814 & .149 & -.017 & .127 & -.043 \\
\hline Original & .005 & .150 & .783 & .128 & -.046 & .179 & .046 \\
\hline Inventive & .065 & .099 & .781 & .234 & -.010 & .184 & .008 \\
\hline Fun & -.097 & .133 & .767 & .042 & -.050 & .105 & -.051 \\
\hline Arouses curiosity & .066 & .130 & .753 & .046 & -.016 & .109 & -.033 \\
\hline \multicolumn{8}{|l|}{ Anxiety (ANX) } \\
\hline Apprehensive & .199 & -.025 & .175 & .911 & -.135 & .144 & -.256 \\
\hline Technical terms & .203 & .084 & .121 & .831 & -.003 & .079 & -.116 \\
\hline Avoided technology & .132 & -.071 & .197 & .894 & .166 & .184 & -.318 \\
\hline Stimulating & .290 & .073 & -.163 & .711 & .160 & -.255 & .119 \\
\hline Overwhelmed & .204 & -.061 & .228 & .741 & -.090 & .122 & -.164 \\
\hline \multicolumn{8}{|l|}{ Complexity (COM) } \\
\hline Complex & -.075 & .116 & -.032 & -.105 & .899 & -.131 & .334 \\
\hline Easy to use & -.097 & .278 & -.030 & -.110 & .898 & -.203 & .552 \\
\hline \multicolumn{8}{|l|}{ Newness (NEW) } \\
\hline New & .121 & .099 & .199 & .136 & -.187 & .931 & .063 \\
\hline Advanced & .113 & .199 & .154 & .121 & -.159 & .940 & .165 \\
\hline \multicolumn{8}{|l|}{ Product Evaluation (PE) } \\
\hline Likable & -.133 & .463 & .012 & -.164 & .489 & .068 & .849 \\
\hline Useful & -.215 & .538 & -.090 & -.290 & .334 & -.085 & .819 \\
\hline Good & -.187 & .390 & -.051 & -.183 & .442 & .108 & .881 \\
\hline Practical & -.153 & .319 & -.047 & -.222 & .600 & -.028 & .845 \\
\hline Worth owning & -.190 & .516 & -.098 & -.298 & .439 & .031 & .872 \\
\hline
\end{tabular}

We posit in Hypothesis 3 that for high NFC individuals, expertise in (a) the primary category and (b) the supplemental category is positively related to DF categorization, and Hypothesis 4 suggests that for low NFC individuals, expertise in (a) the primary category and (b) the supplemental category is also positively related to DFI categorization.

As shown in Fig. 2, the interaction effect between knowledge in the primary category and need for cognition 


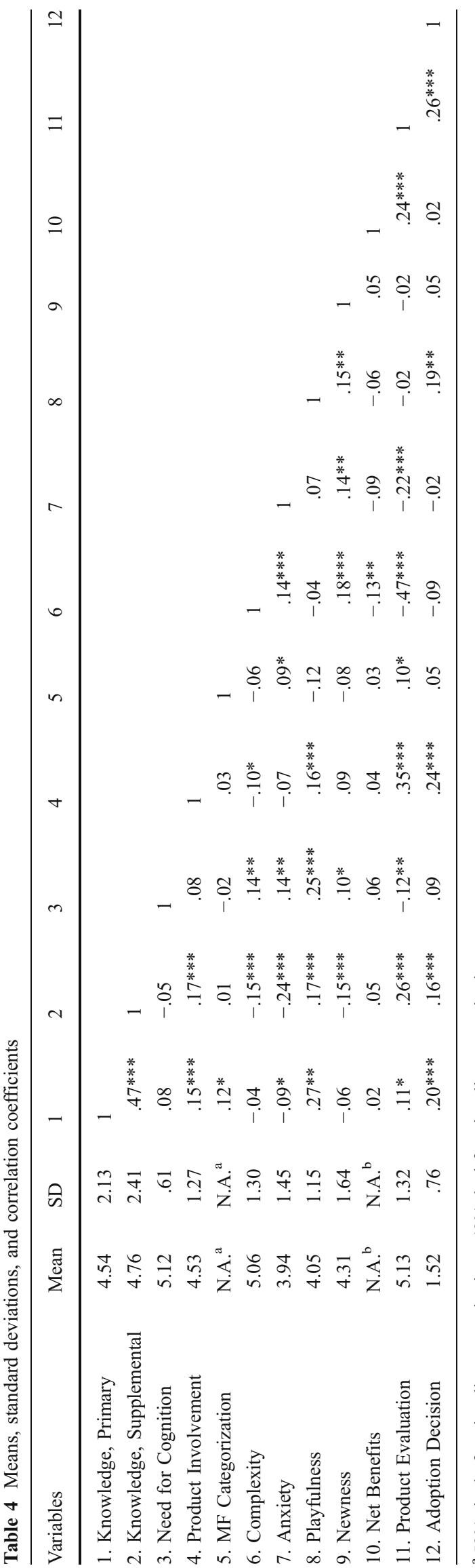

is significant $(\beta=.237, t=1.84, p<.05)$. As the slopes for high and low NFC individuals in the primary category differ (see Fig. 2), H3 (a) and H4 (a) pertaining to the primary category are supported. In contrast, the interaction effect between supplemental category knowledge and need for cognition is non-significant $(\beta=.039, t=.34, p>.10)$ (see Fig. 3). Thus, $\mathrm{H} 3$ and $\mathrm{H} 4$ are supported with respect to primary category knowledge and can thus be considered partially supported.

Hypotheses 5 and 6 examine the interaction effect between DF knowledge and involvement with the expectation that for high-involvement consumers, (a) primary category knowledge and (b) supplemental category knowledge have a positive effect on DFI categorization, whereas for low-involvement consumers, (a) primary category knowledge and (b) supplemental category knowledge have a negative effect on DFI categorization. In the case of (a) primary category knowledge, $\mathrm{H} 5$ and $\mathrm{H} 6$ are supported $(\beta=.463, t=1.99, p<.05$, Figs. 4 and 5$)$, whereas for (b) supplemental category knowledge, $\mathrm{H} 5$ and $\mathrm{H} 6$ are not supported ( $\beta=-.237, t=.94, p>.10$, see Figs. 4 and 5$)$.

According to Hypothesis 7, DF categorization is positively related to product evaluation. As noted by the path coefficient, DF categorization has a significant effect on product evaluation $(\beta=.075, t=1.69, p<.05)$. Therefore, $\mathrm{H} 7$ is supported.

Hypotheses 8-11, pertaining to innovation adoption, propose that net benefits have a positive effect on product evaluation (H8), complexity has a negative effect on product evaluation (H9), newness has a positive effect on product evaluation (H10), and product evaluation has a positive effect on the adoption decision $(\mathrm{H} 11) .{ }^{8}$ With one exception (H10), these hypotheses were supported. As shown in Table 3, all relationships except for the link between product newness and evaluation are statistically significant $(p<.01)$.

Hypotheses $12 \mathrm{a}$ and $12 \mathrm{~b}$ posit interaction effects between technological anxiety and complexity. Specifically, H12a posits that for technologically anxious consumers, complexity is negatively related to product evaluation,

\footnotetext{
${ }^{8}$ We also examined the potential mediating effect of product evaluation on the link between MF categorization and the adoption decision using SEM. As shown in the results, the links between MF categorization and product evaluation and product evaluation and adoption decision are significant (X->.M, M - > Y). However, the link between categorization and the adoption decision is non-significant ( $\beta=.047, t=.60, p>.10)$, as is the $z$-test for mediation $(z=.67, p>.10)$. Based on these results (in which neither the $z$ nor the direct path $\mathrm{X} \rightarrow$ $\mathrm{Y}$ are significant), we may conclude that the mediation is partial and based on the indirect effect of MF categorization on the adoption decision (Iacobucci et al. 2007).
} 
Table 5 Results

\begin{tabular}{|c|c|c|c|c|c|}
\hline Independent variable & Dependent variable & Beta value & $t$-value & $P$ & Hypothesis \\
\hline Knowledge, primary(1) & \multirow[t]{8}{*}{ Dual-functionality Categorization } & .449 & 1.81 & $<.05$ & $\mathrm{H} 1$ \\
\hline Knowledge, supplemental(2) & & .102 & 0.42 & $>.10$ & $\mathrm{H} 2$ \\
\hline NFC & & -.094 & 1.61 & $>.10$ & M.E. \\
\hline Involvement & & -.078 & .94 & $>.10$ & M.E. \\
\hline Knowledge(1) x NFC & & .237 & 1.84 & $<.05$ & $\mathrm{H} 3$ \\
\hline Knowledge(2) x NFC & & .039 & .34 & $>.10$ & $\mathrm{H} 4$ \\
\hline Knowledge(1) x Involvement & & .463 & 1.99 & $<.05$ & H5 \\
\hline Knowledge(2) x Involvement & & -.237 & 0.99 & $>.10$ & H6 \\
\hline Dual-functionality Categorization & \multirow[t]{10}{*}{ Product Evaluation } & .075 & 1.69 & $<.05$ & $\mathrm{H} 7$ \\
\hline Complexity & & -.512 & 6.84 & $<.01$ & H9 \\
\hline Technological Anxiety & & -.176 & 2.99 & $<.01$ & M.E. \\
\hline Playfulness & & -.058 & 0.96 & $>.10$ & M.E. \\
\hline Complexity x Technological Anxiety & & .190 & 2.38 & $<.01$ & $\mathrm{H} 12$ \\
\hline Complexity x Playfulness & & -.148 & 1.87 & $<.05$ & H14 \\
\hline Newness & & .034 & .49 & $>.10$ & $\mathrm{H} 10$ \\
\hline Newness x Technological Anxiety & & -.206 & -2.05 & $<.05$ & H13 \\
\hline Newness x Playfulness & & .264 & 2.89 & $<.01$ & H15 \\
\hline Net Benefits & & .148 & 3.19 & $<.01$ & $\mathrm{H} 8$ \\
\hline Product Evaluation & Adoption Decision & .281 & 5.03 & $<.01$ & H11 \\
\hline
\end{tabular}

whereas $\mathrm{H} 12 \mathrm{~b}$ asserts that complexity is positively related to product evaluation for technologically sophisticated consumers. Our results offer support for the technological anxiety construct as the complexity $\times$ technological anxiety interaction term is significant $(\beta=.190, t=2.38, p<.01$, Fig. 6).

Hypotheses $13 \mathrm{a}$ and $13 \mathrm{~b}$ examine the interaction between technological anxiety and newness, asserting that for more technologically anxious consumers, newness is negatively related to DFI product evaluation, whereas for less technologically anxious consumers, newness is positively related to DFI evaluation. As shown in Fig. 7, this hypothesis is also supported $(\beta=-.206, t=2.05, p<.01)$.

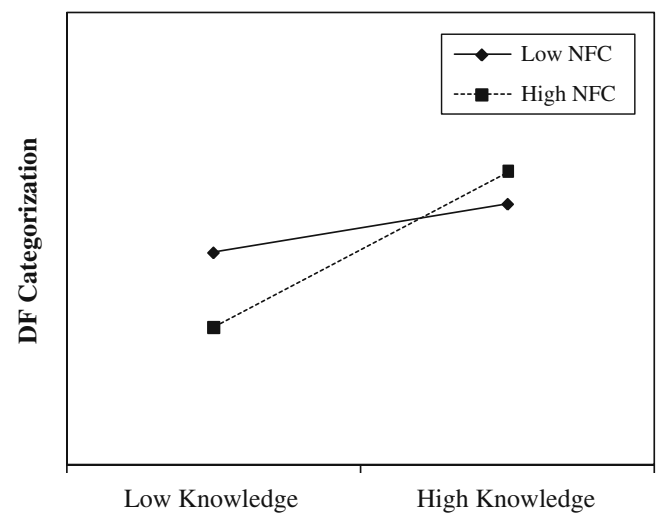

Fig. 2 Primary category knowledge and NFC interaction
Hypothesis 14a proposes that in the case of less playful consumers, complexity is negatively related to product evaluation, whereas Hypothesis $14 \mathrm{~b}$ states that for more playful consumers, complexity is positively related to product evaluation. The interaction effect between playfulness and complexity is significant $(\beta=-.148, t=1.87, p<.01)$, but as shown in Fig. 8, H14b is not supported. Finally, H15 examines the interaction between newness and playfulness, predicting that for less playful consumers, newness is negatively related to product evaluation whereas for more playful consumers, newness is positively related to product evaluation. As shown in Fig. 9, H15 is supported $(\beta=.264, t=2.90, p<.01)$.

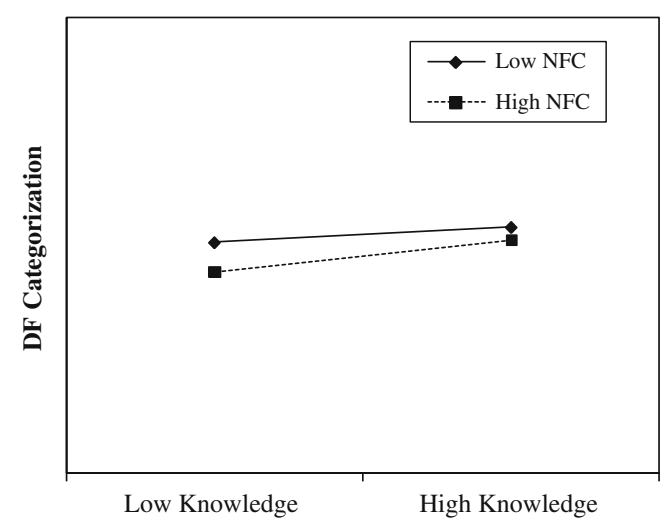

Fig. 3 Supplemental category knowledge and NFC interaction 


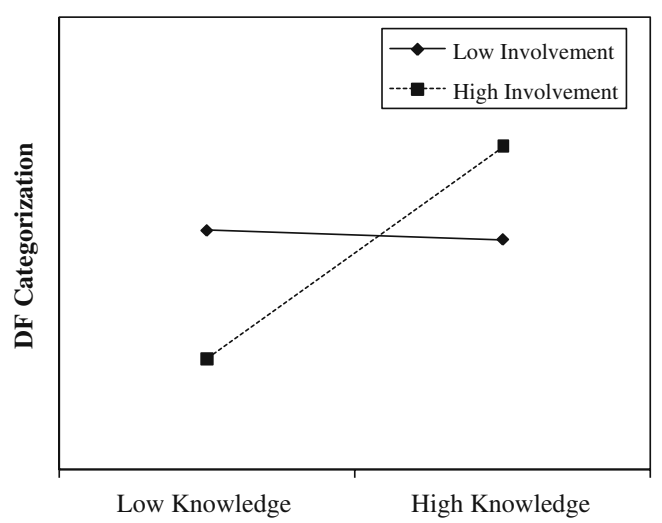

Fig. 4 Primary category knowledge and involvement interaction

Estimating the adequacy of the model

To establish the added value of including the MOA factors in a model of innovation adoption, we compared the proposed model to the traditional innovation adoption model incorporating innovation characteristics as the only predictors of product evaluation; that is, the MOA factors were excluded. The results show that the model is acceptable except in the case of its RMSEA value $\left(\chi^{2} / \mathrm{df}=\right.$ $3.57, \mathrm{RMSEA}=.088, \mathrm{RMR}=.047, \mathrm{GFI}=.940, \mathrm{AGFI}=.900$, $\mathrm{NFI}=.931$ and $\mathrm{CFI}=.949)$. A $\chi^{2}$ comparison test shows that the proposed model has superior predictive power as compared to the traditional innovation adoption model $\left(\chi_{\text {diff. }}{ }^{2}(19)=60.20, p<01\right)$. Thus, our results support assertions in the literature that the inclusion of the MOA framework in a model of MFI adoption significantly improves its predictive power.

\section{A rival model}

In conceptualizing the influences of technological anxiety and playfulness, it is plausible to propose a relationship between existing primary and supplemental category knowledge and technological anxiety and playfulness. ${ }^{9}$ The argument leading to a plausible alternative model posits that greater category knowledge may reduce anxiety while increasing playfulness in consumers. Additionally, an alternative model may include a path to demonstrate a potential relationship between technological anxiety and playfulness with net benefits. It may also be plausible that greater technological anxiety leads to greater perceived risk and/or lower relative advantage and, hence, lower net benefits.

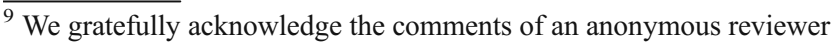
about this plausible rival model.
}

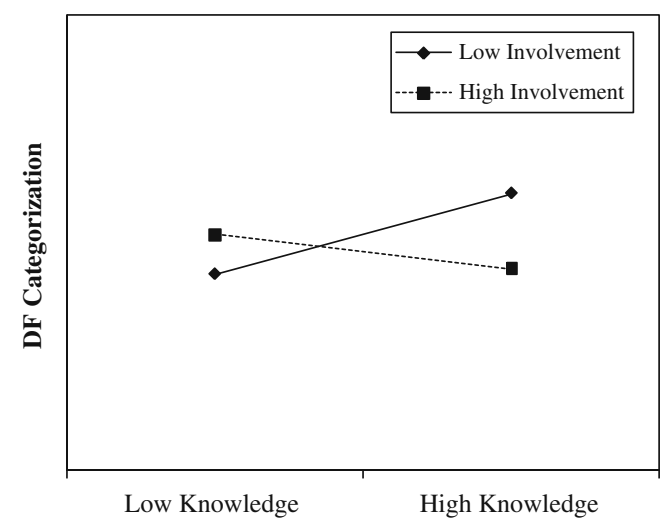

Fig. 5 Supplemental category knowledge and involvement interaction

Given this scenario, we tested a rival model in which knowledge (primary and supplemental) influences technological anxiety and playfulness that, in turn, influence net benefits. The model has acceptable fit $\left(\chi^{2} / \mathrm{df}=3.60\right.$, $\mathrm{RMSEA}=.090, \mathrm{RMR}=.099, \mathrm{GFI}=.816, \mathrm{AGFI}=.721$, $\mathrm{NFI}=.832$ and $\mathrm{CFI}=.857$ ), although the RMSEA value is somewhat greater than the accepted guidelines would recommend (Browne and Cudeck 1993). Of the additional paths, only three of the six paths are significant, demonstrating that the proposed model is more parsimonious than the alternative model. Importantly, a $\chi^{2}$ comparison test shows that the proposed model has significantly superior fit vis-à-vis the rival model $\left(\chi_{\text {diff. }}^{2}\right.$ $(6)=24.20, p<.01)$. Collectively, this evidence enhances the confidence in the proposed model.

\section{Discussion}

The proliferation of MF high-tech products heightens consumers' reliance on motivational resources. The fusion of two or more functionalities may easily lead to confusion about the new product's purpose and benefits. In responding

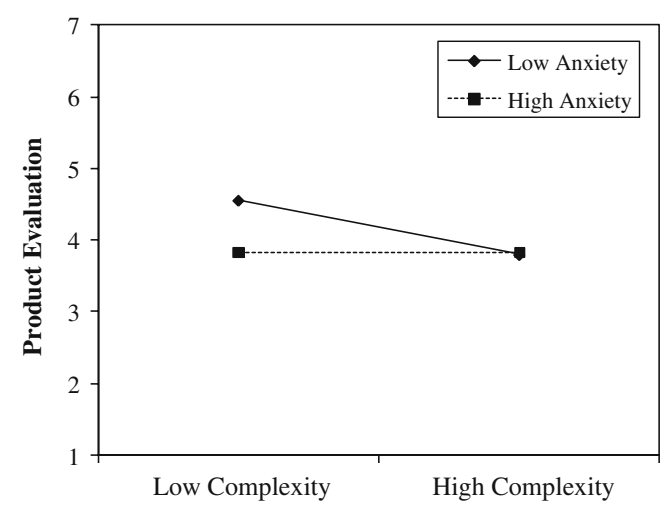

Fig. 6 Complexity and technological anxiety interaction 


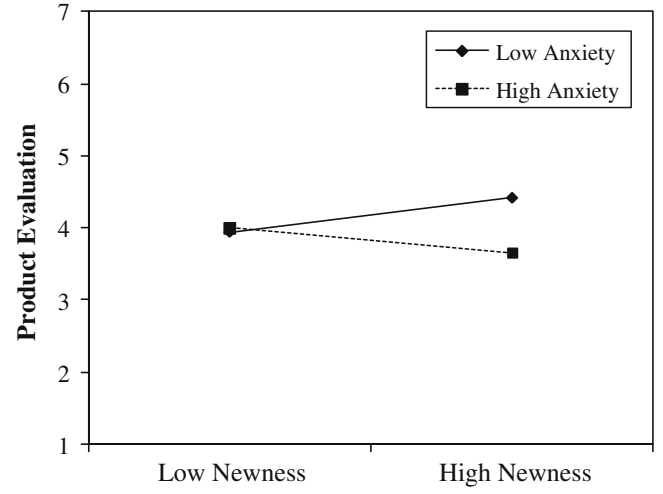

Fig. 7 Newness and technological anxiety interaction

to a call for developing more integrative frameworks, we proposed and tested a model for assessing new MF product evaluation and adoption using DFIs as the basis for our investigation. Our model incorporates the MOA framework from the information processing literature (MacInnis et al. 1991) in combination with the adoption of innovations model presented by Rogers $(1962,2003)$. The results show that the proposed model is superior to the traditional innovation adoption model presented by Rogers, while adding new insights into the area of innovation adoption.

The model presented in this study offers three new insights. The first and foremost observation relates to the allencompassing role of motivation in categorizing and evaluating MF products. Our results clearly demonstrate that motivation is essential for assessing DF products in particular, and by extension for more complex innovations. They further indicate that assessing new product adoption on the basis of only the traditional innovation adoption model can yield misleading results. As most innovations in the consumer electronics sector nowadays incorporate elements from several categories and thereby tend to be quite complex, the role of motivational resources is essential for a more accurate assessment of consumer adoption of high-tech innovations.

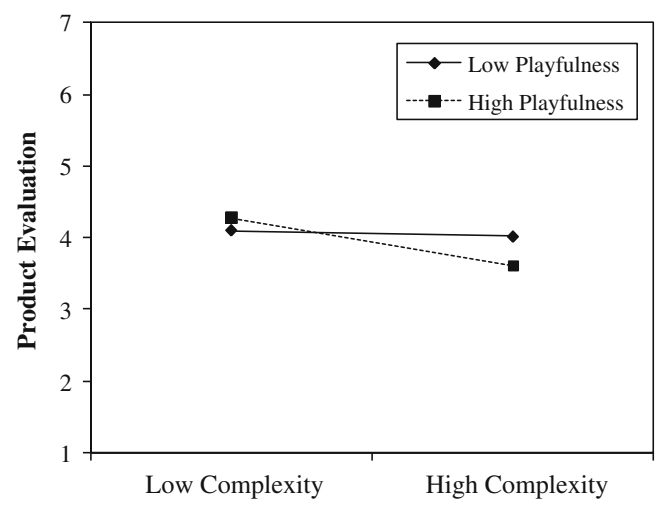

Fig. 8 Complexity and playfulness interaction

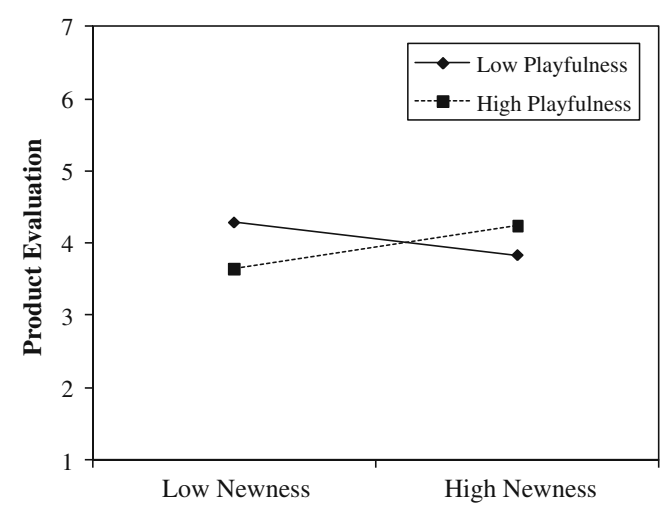

Fig. 9 Newness and playfulness interaction

The role of motivation in innovation adoption also yields concrete, actionable recommendations to marketers. For example, motivation can be enhanced by providing stimulating packaging and/or appealing product designs that raise product interest and facilitate comprehension (Creusen and Schoormans 2005). Also, training consumers to use a new electronic product raises motivation by making consumers feel more knowledgeable and competent about product use. This can be implemented by designing distribution plans for retailers that invite and encourage consumers to test and use the multiple features and functionalities of the product at the store level (Lakshmanan et al. 2010). The Internet offers an additional avenue for motivating consumers, for example, by providing demonstrations of the firm's MFI as well as handson training videos that reduce anxiety and complexity in using the product.

Second, our results show that dual-functionality categorization contributes to more positive product evaluations. Dualfunctionality categorization highlights the attainment of multiple, complementary goals, which renders the DFI superior to the SF version of the same product. Considering the myriad of products that combine functionalities, the focus on communicating the complementary goals provided by the product becomes essential in targeting new buyers. Despite its importance, MF categorization has not been addressed in the innovation adoption literature. To enhance high-tech innovation adoption rates, Rogers (2003) called for research to determine how the hardware and software components of high-tech products interact. As MF products often build on such interactions to produce their complementary goals, this study is a first step toward addressing this issue.

Third, our results demonstrate that the role of the innovation characteristics of complexity and newness have effects on adoption that are contingent rather than absolute. Considering the vast number of studies addressing complexity and newness and the importance associated with them, this finding is important. As we demonstrate, the negative effect of these components can be reversed by 
evoking positive affect (in the form of playfulness) and reducing negative affect (in the form of anxiety). Other affective reactions (such as joy and excitement) could also be evoked to stimulate similar results. This finding can also be used for market segmentation, thereby allowing marketers to target specific users based on their affective reactions. For example, non-anxious and playful consumers that enjoy complex products could be granted first access to new MFIs to demonstrate product capabilities, promote social visibility, and visualize the use of the product. From a product development perspective, making product usage fun and varied by providing customization options and social media capabilities increases consumer response to MFIs and should therefore be encouraged.

In general, within the context of the study's setting, our results demonstrate that the proposed integrative model is a reliable predictor of consumer adoption of MF innovations and bring several new insights to the literature on innovation adoption. With the exceptions of the interaction terms between supplemental knowledge and mental resources as well as the interaction between complexity and playfulness, all hypotheses were supported. Importantly, the predictive power of the model was found to be significant despite its greater complexity. These results show that the predictive power of the traditional innovation adoption model presented by Rogers is improved when augmented by the MOA model.

\section{Conclusions and managerial implications}

An important way for firms to differentiate their offers is to add more functionality to their products (cf., Gregan-Paxton et al. 2005; Ziamou and Ratneshwar 2002, 2003). This strategy and the necessity to differentiate offerings are evident by the very large number of new products marketed annually. ${ }^{10}$ In particular, a focus on MFIs is justified because they are a less risky alternative to developing really new products. Indeed, many firms view MFIs as a means to gain market share, withstand the heightened competitive pressure, and/or combat declining profits (Noam 2005). The rapid pace of introducing new MF high-tech innovations creates a major challenge for firms in appropriately positioning their new offers. Product managers face a strategic decision of critical importance: how to reduce uncertainty in new product development and introduction such that adoption rates are higher relative to the competition and the new product meets its stated objectives.

\footnotetext{
${ }^{10}$ According to the Global New Products Database, in the global consumer packaged goods sectors alone over 460,000 new products are introduced annually (www.gnpd.com, March 2005), the majority of which are differentiated versions of existing products.
}

Ultimately, the success of any MFI hinges upon how well the firm communicates its benefits to intended target markets. The findings of the present study provide essential components for developing effective marketing plans for new MFIs. First, managers should strive to evoke a dualfunctionality categorization in their products to heighten complementary goals and yield positive product evaluations. For example, Apple uses this strategy, calling the iPod Touch "a great music player, pocket computer, and portable game player." They also advertise the iPad based on convergence and state that the iPad is "the best way to experience the web, email, photos, and video." Products can also be designed to evoke multiple-functionality categorization by including visual cues from all product categories combined in the MFI (Creusen and Schoormans 2005). Creative communication such as visually blending the product categories in the MFI is also likely to increase motivation by facilitating the processing of MFIs.

Second, motivation can be enhanced by evoking positive emotions and reducing negative ones. Positive emotions can be enhanced by providing customization options and, where applicable, add-on options (e.g., varied software applications) that make the MFI more varied and exciting. Providing diverse product experiences attracts consumers to MFIs and makes them more receptive to their use. To reduce negative emotions, firms can provide instructions and advice regarding the product and develop tutorials for product use. Instructions regarding product use help teach consumers about complex products and thereby facilitate product adoption. Future research should extend our model by focusing on the effects of positive and negative emotions on innovation adoption. Emotions have been sparsely addressed in the innovation adoption literature (Wood and Moreau 2006) and represent a fruitful area for future investigation. Further, the predictive validity of our model could also be tested and potentially increased by adding contextual specificity to it, such as the purchase location and number of brands purchased (Warshaw 1980). This would also constitute a useful avenue for future research on MFIs, since the preference toward MFIs can vary based on the composition of the choice set and the number of products considered. Beyond innovation adoption, subsequent use of innovations also demands further research. For example, playful consumers might have a wider breadth of product usage than non-playful ones and might be more willing to try out the array of functions offered by an MFI. A research agenda addressing these issues complements the extant knowledge.

Open Access This article is distributed under the terms of the Creative Commons Attribution Noncommercial License which permits any noncommercial use, distribution, and reproduction in any medium, provided the original author(s) and source are credited. 


\section{Appendix}

This new camera phone has, among other things:

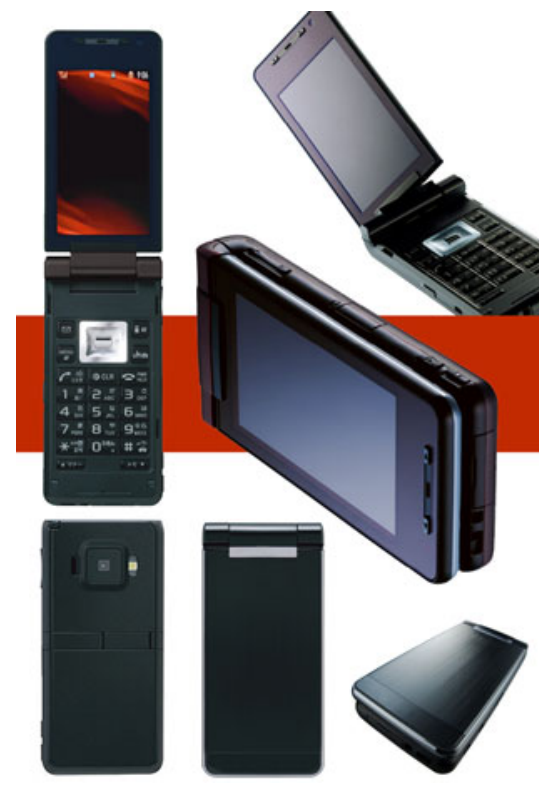

\footnotetext{
- Touch screen for easy dialing

- 5 megapixel camera

- Lithium -ion battery

- Messaging (SMS, MMS)

- Built -in flash and facial recognition

- USB connectivity

- Movie recording

1 GB Flash memory
}

$\square$ Mobile TV, internet and e-mail

The camera phone is delivered with a 5-megapixel autofocus digital camera. The camera phone has $3 G$ support, enabling fast internet access and mobile TV. With the multimedia player, both music and films can be played, and the multimedia messaging (MMS) feature allows for sending pictures and film clips

to friends. The camera phone includes a flash and facial recognition. In addition, this camera phone gives you the opportunity to make video recordings. In the menu, icons give you access to the address book, messages, call records, multimedia, games, setup, services and documents.

\section{References}

Alba, J. W., \& Hutchinson, J. W. (1987). Dimensions of consumer expertise. Journal of Consumer Research, 13(4), 411-454.

Anderson, J. C., \& Gerbing, D. W. (1988). Structural equation modeling in practice: a review and recommended two-step approach. Psychological Bulletin, 103(3), 411-423.

Batra, R., \& Ray, M. L. (1986). Situational effects of advertising repetition: the moderating influence of motivation, ability, and opportunity to respond. Journal of Consumer Research, 12(4), 432-445.
Bauer, R. A. (1960). Consumer behavior as risk taking. In R. S. Hancock (Ed.), Dynamic Marketing for a Changing World, Proceedings of the 43rd Conference of the American Marketing Association (pp. 389-398). Chicago: American Marketing Association.

Binney, W., Hall, J., \& Shaw, M. (2003). A further development in social marketing: application of the MOA framework and behavioral implications. Marketing Theory, 3(3), 387-403.

Browne, M. W., \& Cudeck, R. (1993). Alternative ways of assessing model fit. In K. A. Bollen \& J. S. Long (Eds.), Testing structural equation models (pp. 136-162). Beverly Hills: Sage.

Byrne, B. M. (2010). Structural equation modeling with AMOS. New York: Routledge. 
Cacioppo, J. T., \& Petty, R. E. (1982). The need for cognition. Journal of Personality and Social Psychology, 42(1), 116-131.

Cacioppo, J. T., Petty, R. E., \& Morris, K. (1983). Effects of need for cognition on message evaluation, recall, and persuasion. Journal of Personality and Social Psychology, 45, 805-818.

Cacioppo, J. T., Petty, R. E., \& Kao, C. F. (1984). The efficient assessment of need for cognition. Journal of Personality Assessment, 48(3), 306-307.

Campbell, M. C., \& Goodstein, R. C. (2001). The moderating effect of perceived risk on consumers' evaluations of product incongruity: preference for the norm. Journal of Consumer Research, 28(3), 439-449.

Celsi, R. L., \& Olson, J. C. (1988). The role of involvement in attention and comprehension processes. Journal of Consumer Research, 15(2), 210-224.

Chin, W. W. (1998). The partial least squares approach to structural equation modeling. In G. A. Marcoulides (Ed.), Modern methods for business research (pp. 295-336). Mahwah: Lawrence Erlbaum Associates.

Clark, B. H., Abela, A. V., \& Ambler, T. (2005). Organizational motivation, opportunity and ability to measure marketing performance. Journal of Strategic Marketing, 13, 241-259.

Cotte, J., \& Wood, S. (2004). Families and innovative consumer behavior: a triadic study of siblings and parents. Journal of Consumer Research, 31(1), 78-86.

Creusen, M. E. H., \& Schoormans, J. P. L. (2005). The different roles of product appearance in consumer choice. Journal of Product Innovation Management, 22(1), 63-81.

Dickerson, M. D., \& Gentry, J. W. (1983). Characteristics of adopters and non-adopters of home computers. Journal of Consumer Research, 10(2), 225-235.

Estes, Z., \& Ward, T. B. (2002). The emergence of novel attributes in concept modification. Creativity Research Journal, 2(14), 149156.

Fang, X., Chan, S., Brzezinski, J., \& Shuang, X. (2005-2006). Moderating effects of task type on wireless technology acceptance. Journal of Management Information Systems, 22(3), 123157.

Fishbach, A., \& Dhar, R. (2007). Dynamics of goal-based choice. In C. P. Haugtvedt, P. M. Herr, \& F. R. Kardes (Eds.), Handbook of consumer psychology (pp. 611-637). New York: Psychology.

Fishbach, A., \& Ferguson, M. F. (2007). The goal construct in social psychology. In A. W. Kruglanski \& T. E. Higgins (Eds.), Social psychology: Handbook of basic principles (pp. 490-515). New York: Guilford.

Fishbach, A., \& Zhang, Y. (2008). Together or apart: when goals and temptations complement versus compete. Journal of Personality and Social Psychology, 94, 547-559.

Fornell, C., \& Bookstein, F. L. (1982). Two structural equation models: LISREL and PLS applied to consumer exit-voice theory. Journal of Marketing Research, 19(4), 440-452.

Fornell, C., \& Larcker, D. F. (1981). Evaluating structural equation models with unobservable variables and measurement error. Journal of Marketing Research, 18(1), 39-50.

Gagné, C. L., \& Shoben, E. J. (1997). The influence of thematic relations on the comprehension of non-predicating conceptual combinations. Journal of Experimental Psychology: Learning, Memory, and Cognition, 23, 71-87.

Gatignon, H., \& Robertson, T. S. (1985). A propositional inventory for new diffusion research. Journal of Consumer Research, 11(4), $849-867$.

Gill, T. (2008). Convergent products: What functionalities add more value to the base? Journal of Marketing, 72(2), 46-62.

Gill, T., \& Dubé, L. (2007). What is a leather iron or a bird phone? Using conceptual combinations to generate and understand new product concepts. Journal of Consumer Psychology, 17(3), 202217.

Gregan-Paxton, J., Hoeffler, S., \& Zhao, M. (2005). When categorization is ambiguous: factors that facilitate the use of a multiple category inference strategy. Journal of Consumer Psychology, 15 (2), 127-140.

Gruen, T. W., Osmonbekov, T., \& Czaplewski, A. J. (2007). Customer-to-customer exchange: its MOA antecedents and its impact on value creation and loyalty. Journal of the Academy of Marketing Science, 35(4), 537-549.

Han, J. K., Chung, S. W., \& Sohn, Y. S. (2009). Technology convergence: When do consumers prefer converged products to dedicated products? Journal of Marketing, 73, 97-108.

Haugtvedt, C. P., Petty, R. E., \& Cacioppo, J. T. (1992). Need for cognition and advertising: understanding the role of personality variables in consumer behavior. Journal of Consumer Psychology, 1(3), 239-260.

Hirschman, E. C., \& Holbrook, M. B. (1982). Hedonic consumption: emerging concepts, methods and propositions. Journal of Marketing, 46(3), 92-101.

Hoeffler, S. (2003). Measuring preferences for really new products. Journal of Marketing Research, 40(4), 406-420.

Holak, S. L. (1988). Determinants of innovative durable adoption: an empirical study with implications for early product screening. Journal of Product Innovation Management, 5, 50-69.

Holak, S. L., \& Lehmann, D. R. (1990). Purchase intentions and the dimensions of innovation: an exploratory model. Journal of Product Innovation Management, 7, 59-73.

Holbrook, M. B., Chestnut, R. W., Olivia, T. A., \& Greenleaf, E. A. (1984). Play as a consumption experience: the roles of emotions, performance, and personality in the enjoyment of games. Journal of Consumer Research, 11(2), 728-739.

Iacobucci, D., Saldanha, N., \& Deng, X. (2007). A meditation on mediation: evidence that structural equations models perform better than regressions. Journal of Consumer Psychology, 17(2), $140-154$.

Igbaria, M., \& Parasuraman, S. (1989). A path analytic study of individual characteristics, computer anxiety and attitudes toward microcomputers. Journal of Management, 15(3), 373-388.

Jöreskog, K. G., \& Sörbom, D. (1982). Recent developments in structural equation modeling. Journal of Marketing Research, 19 (4), 404-416.

Kopalle, P. K., \& Lindsey-Mullikin, J. (2003). The impact of external reference price on consumer price expectations. Journal of Retailing, 79(4), 225-236.

Kruglanski, A. W., Shah, J. Y., Fishbach, A., Friedman, R. S., Chun, W. Y., \& Sleeth-Keppler, D. (2002). A theory of goal systems: implications for social cognition, affect, and action. In M. Zanna (Ed.), Advances in experimental social psychology, 34 (pp. 331376). New York: Academic.

Lakshmanan, A., Lindsey, C. D., \& Krishnan, H. S. (2010). Practice makes perfect? When does massed learning improve product usage proficiency? Journal of Consumer Research, 37(December), forthcoming.

Liebermann, Y., \& Flint-Goor, A. (1996). Message strategy by product-class type: a matching model. International Journal of Research in Marketing, 13(3), 237-249.

MacInnis, D. J., \& Jaworski, B. J. (1989). Information processing from advertisements: toward an integrative framework. Journal of Marketing, 53, 1-23.

MacInnis, D. J., Moorman, C., \& Jaworski, B. J. (1991). Enhancing and measuring consumers' motivation, opportunity, and ability to process brand information from ads. Journal of Marketing, 55(4), 32-53.

Mandler, G. (1982). The structure of value: Accounting for taste. In M. S. Clark \& S. T. Fiske (Eds.), Affect and cognition: The 17th 
annual Carnegie symposium (pp. 3-36). Hillsdale: Lawrence Erlbaum Associates.

Mantel, S. P., \& Kardes, F. R. (1999). The role of direction of comparison, attribute-based processing, and attitude-based processing in consumer preference. Journal of Consumer Research, 25(4), 335-352.

Markman, A. B. (2001). Knowledge representation. Mahwah: Lawrence Erlbaum Associates.

Meuter, M. L., Ostrom, A. L., Bitner, M. J., \& Roundtree, R. (2003). The influence of technology anxiety on consumer use and experiences with self-service technologies. Journal of Business Research, 56, 899-906.

Meuter, M. L., Bitner, M. J., Ostrom, A. L., \& Brown, S. W. (2005). Choosing among alternative service delivery modes: an investigation of customer trial of self-service technologies. Journal of Marketing, 69(2), 61-83.

Meyers-Levy, J., \& Tybout, A. M. (1989). Schema congruity as a basis for product evaluation. Journal of Consumer Research, 16 (1), 39-54.

Mick, D. G., \& Fournier, S. (1998). Paradoxes of technology: consumer cognizance, emotions, and coping strategies. Journal of Consumer Research, 25(2), 123-143.

Moon, J.-W., \& Kim, Y.-G. (2001). Extending the TAM for a world-wide-web context. Information and Management, 38, 217-230.

Moore, G. C., \& Benbasat, I. (1991). Development of an instrument to measure perceptions of adopting an information technology innovation. Information Systems Research, 2(3), 192-222.

Moreau, C. P., Lehmann, D. R., \& Markman, A. B. (2001). Entrenched knowledge structures and consumer response to new products. Journal of Marketing Research, 38(1), 14-29.

Noam, E. (2005). A dim future for consumer electronics? Financial Times, March 3.

Parasuraman, A. (2000). Technology readiness index (TRI): a multiple-item scale to measure readiness to embrace new technology. Journal of Service Research, 2(4), 307-320.

Petty, R. E., \& Cacioppo, J. T. (1986). The elaboration likelihood model of persuasion. New York: Academic.

Petty, R. E., Cacioppo, J. T., \& Schumann, D. (1983). Central and peripheral routes to advertising effectiveness: the moderating role of involvement. Journal of Consumer Research, 10(2), 135-146.

Pogue, D. (2007). Apple waves its wand at the phone. The New York Times, January 11.

Priluck, R., \& Till, B. D. (2004). The role of contingency awareness, involvement, and need for cognition in attitude formation. Journal of the Academy of Marketing Science, 32(3), 329-344.

Richins, M. L., \& Bloch, P. H. (1986). After the new wears off: the temporal context of product involvement. Journal of Consumer Research, 13, 280-285.

Roberts, J. H. (2000). Developing new rules for new markets. Journal of the Academy of Marketing Science, 28(1), 31-44.

Robertson, T. S. (1971). Innovative behavior and communication. New York: Holt Rinehart and Winston Inc.

Roehm, M. L., \& Sternthal, B. (2001). The moderating effect of knowledge and resources on the persuasive impact of analogies. Journal of Consumer Research, 28(2), 257-272.

Rogers, E. M. (1962). Diffusion of innovations. New York: The Free.

Rogers, E. M. (2003). Diffusion of innovations (5th ed.). New York: The Free.

Schumacker, R. E., \& Lomax, R. G. (2004). A beginner's guide to structural equation modeling (2nd ed.). Mahwah: Lawrence Erlbaum Associates.

Shrum, L. J., Burroughs, J. E., \& Rindfleisch, A. (2005). Television's cultivation of material values. Journal of Consumer Research, 32 (3), 473-479.
Szymanski, D., Kroff, M. W., \& Troy, L. C. (2007). Innovativeness and new product success: insights from the cumulative evidence. Journal of the Academy of Marketing Science, 35(1), 35-52.

Taylor, S., \& Todd, P. (1995). Decomposition crossover effects in the theory of planned behavior: a study of consumer adoption intentions. International Journal of Research in Marketing, 12 (2), 137-155.

Tidwell, P. S., Sadowski, C. J., \& Pate, L. M. (2000). Relationships between need for cognition, knowledge, and verbal ability. The Journal of Psychology, 134(6), 634-644.

Tornatzky, L. G., \& Klein, K. J. (1982). Innovation characteristics and innovation adoption-implementation: a meta-analysis of findings. IEEE Transactions on Engineering Management, 29, $28-45$.

Venkatesh, V. (2000). Determinants of perceived ease of use: integrating control, intrinsic motivation, and emotion into the technology acceptance model. Information Systems Research, 11 (4), 342-365.

Von Hippel, E. (1986). Lead users: a source of novel product concepts. Management Science, 32(7), 791-805.

Warshaw, P. R. (1980). A new model for predicting behavioral intentions: an alternative to Fishbein. Journal of Marketing Research, 17, 153-172.

Webster, J., \& Martocchio, J. (1992). Microcomputer playfulness: development of a measure with workplace implications. MIS Quarterly, 16(2), 201-226.

Webster, J., \& Martocchio, J. (1993). Turning work into play: implications for microcomputer software training. Journal of Management, 19(1), 127-146.

Wilkenfeld, M. J., \& Ward, T. B. (2001). Similarity and emergence in conceptual combination. Journal of Memory and Language, 45, 21-38.

Wisniewski, E. J. (1995). Prior knowledge and functionally relevant features in concept learning. Journal of Experimental Psychology: Learning, Memory, and Cognition, 21(2), 449-468.

Wisniewski, E. J. (1996). Construal and similarity in conceptual combination. Journal of Memory and Language, 35(3), 434 453.

Wisniewski, E. J. (1997). When concepts combine. Psychonomic Bulletin and Review, 4(2), 167-183.

Wisniewski, E. J., \& Love, B. C. (1998). Relations versus properties in conceptual combination. Journal of Memory and Language, $38,177-202$.

Wood, S. L., \& Swait, J. (2002). Psychological indicators of innovation adoption: cross-classification based on need for cognition and need for change. Journal of Consumer Psychology, 12(1), 1-13.

Wood, S. L., \& Moreau, C. P. (2006). From fear to loathing? How emotion influences the evaluation and early use of innovations. Journal of Marketing, 70, 44-57.

Wu, Y., Balasubramanian, S., \& Mahajan, V. (2004). When is a preannounced new product likely to be delayed? Journal of Marketing, 68, 101-113.

Zaichkowsky, J. L. (1985). Measuring the involvement construct. Journal of Consumer Research, 12(3), 341-352.

Zaichkowsky, J. L. (1994). The personal involvement inventory: reduction, revision, and application to advertising. Journal of Advertising, 23(4), 59-70.

Ziamou, P., \& Ratneshwar, S. (2002). Promoting consumer adoption of high-technology products: Is more information always better? Journal of Consumer Psychology, 12(4), 341-351.

Ziamou, P., \& Ratneshwar, S. (2003). Innovations in product functionality: When and why are explicit comparisons effective? Journal of Marketing, 67(2), 49-61. 